\title{
Hydrographic influences on the summer dive behaviour of Weddell seals (Leptonychotes weddellii) in Atka Bay, Antarctica
}

\author{
T. McIntyre $\cdot$ L. J. Stansfield $\cdot$ H. Bornemann • \\ J. Plötz $\cdot$ M. N. Bester
}

Received: 15 April 2013/Revised: 29 July 2013/Accepted: 6 August 2013/Published online: 22 August 2013

(C) The Author(s) 2013. This article is published with open access at Springerlink.com

\begin{abstract}
In order to gain insights into species-level behavioural responses to the physical environment, it is necessary to obtain information from various populations and at all times of year. We analysed the influences of physical environmental parameters on the mid-summer dive behaviour of Weddell seals (Leptonychotes weddellii) from a little-known population at Atka Bay, Antarctica. Dive depth distributions followed a typical bimodal pattern also exhibited by seals from other populations and seals targeted both shallow water layers of $<50 \mathrm{~m}$ and depths near the seafloor. Increased stratification of temperature layers within the water column resulted in increased forage efforts by the seals through relatively high numbers of dives to the seafloor, as well as forage effort associated with shallow dives. We interpret these behavioural responses to be due to increased water temperature stratification resulting in the concentration of prey species in particular depth layers.
\end{abstract}

Keywords Satellite Relay Data Logger . Temperature stratification - Forage effort .

Behavioural response

Electronic supplementary material The online version of this article (doi:10.1007/s00300-013-1384-7) contains supplementary material, which is available to authorized users.

T. McIntyre $(\bowtie) \cdot$ L. J. Stansfield · M. N. Bester Mammal Research Institute, Department of Zoology and Entomology, University of Pretoria, Private Bag X20, Hatfield 0028, South Africa

e-mail: tmcintyre@zoology.up.ac.za

T. McIntyre $\cdot$ H. Bornemann $\cdot$ J. Plötz

Alfred Wegener Institut, Helmholtz-Zentrum für Polar-und Meeresforschung, Postfach 120161, 27515 Bremerhaven, Germany

\section{Introduction}

Understanding how the movements and behaviour of animals are related to their physical environment is integral to gain insights into the likely influences of anthropogenicdriven environmental changes on various animal populations. Advances in technology allowed recent studies of the movements and dive behaviours of marine predators in relation to their in situ environment (e.g. McIntyre et al. 2011; Bestley et al. 2013). While such studies are useful to provide first insights into the likely responses of marine animals to changes in the physical environment, its interpretation with regard to species-level influences can be complicated by limitations of individual-based extrapolations (Holdo and Roach 2013), as well as the potential influences of inter-population differences in behaviour (Fossette et al. 2010; James et al. 2012).

Weddell seals (Leptonychotes weddellii) are amongst the most well-studied marine vertebrates, and much is known about their spatial movements and dive behaviour (e.g. Southwell et al. 2012 and the references therein). Some influences of bathymetric and in situ hydrographic properties on the spatial movements and dive behaviour of Weddell seals were also described for seals tracked during austral winter months, suggesting that seals favoured shallow water bodies, comparatively even bathymetry and specific water masses (Antarctic Surface Water and Modified Circumpolar Deep Water) (Heerah et al. 2013). However, studies on the spatial movements and dive behaviour of Weddell seals have mostly been restricted to experiments carried out at a small number of localities in the Antarctic, namely McMurdo Sound (e.g. Burns et al. 1999; Harcourt et al. 2000; Sato et al. 2002; Davis et al. 2003; Williams et al. 2004), Syowa Station (e.g. Sato et al. 2002, 2003), Drescher Inlet (e.g. Bornemann et al. 1998; 
Plötz et al. 2001; Watanabe et al. 2006) and Dumont D’Urville (e.g. Heerah et al. 2013) (Fig. 1). Here, we report on the mid-summer horizontal and vertical habitat use in relation to in situ environmental parameters of Weddell seals from a little-known population in Atka Bay, Antarctica.

\section{Materials and methods}

\section{Instrumentation}

We deployed six CTD-Satellite Relay Data Loggers (Sea Mammal Research Unit, University of St. Andrews, Scotland) on Weddell seals hauled out along tidal cracks in Atka Bay $\left(70^{\circ} 39^{\prime} \mathrm{S}, 08^{\circ} 15^{\prime} \mathrm{W}\right)$, near Neumayer Station, Antarctica, between mid-November and mid-December 2008. At the time of deployment, approximately 50 seals were present in the Atka Bay colony and the instrumented seals were part of groups of seals hauled out at two whelping patches (van Opzeeland et al. 2012). CTDSRDLs are capable of recording and transmitting temperature data with accuracy better than $0.005{ }^{\circ} \mathrm{C}$ and salinity measures with accuracy better than 0.02 (Boehme et al. 2009). Devices were calibrated by the manufacturer
(SMRU) prior to deployment. Since the devices were not retrieved post-deployment (but moulted off and lost), no post-deployment calibrations were possible. Expected accuracies, without post-deployment calibration, were $\pm 0.02{ }^{\circ} \mathrm{C}$ for temperature and 0.1 for derived salinity (Roquet et al. 2011). Devices were deployed on the fur on the heads of four adult seals (two males and two nonlactating females) and on the fur on the dorsal midline posterior to the scapulae on two recently weaned seals (one female and one male), using a quick-setting epoxy resin (Araldite, Ciba-Geigy ${ }^{\mathrm{TM}}$ ). Adult seals were immobilised by remote intra-muscular injection of pre-calculated dosages of xylazine-ketamine, and anaesthesia maintained by additional injections of ketamine. Juvenile seals were temporarily restrained with a head bag and then anaesthetised with sevoflurane gas inhalant, using a custom-made, portable anaesthesia system. Information obtained from all satellite-linked devices is stored in the PANGAEA data archive (www.pangaea.de). Details of the individual datasets used are reported in Online Resource 1.

\section{Behavioural data}

Track data were filtered, first by removing all location points of location quality worse than 0 (i.e. where no
Fig. 1 Envisat ASAR image of the shelf ice contour around Atka Bay, with estimated dive locations of the tracked Weddell seals illustrated. Image taken on 15-11-2008 centred at $70^{\circ} 42^{\prime} \mathrm{S}$; $8^{\circ} 44^{\prime} \mathrm{W}$. Inset Map of

Antarctica showing the locations of other studies on the movements and dive behaviours of Weddell seals. MS McMurdo Sound, $D I$ Drescher Inlet, $A B$ Atka Bay, $D D$ Dumont D'Urville, SS Syowa Station

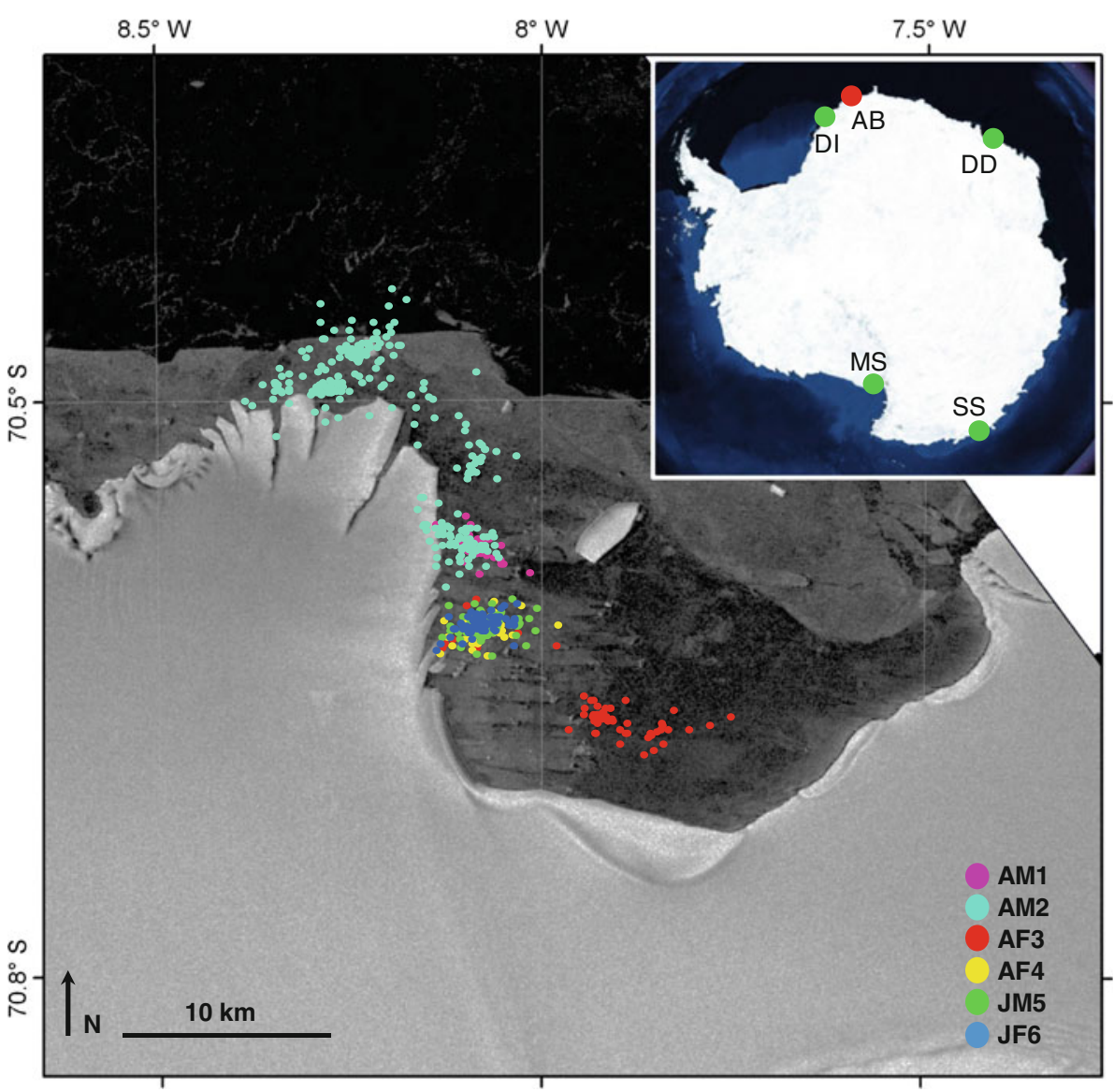


accuracy was assigned by Service Argos), and then based on assumed maximum swim speeds and turning angles (Freitas et al. 2008). Filtered tracks were illustrated in ArcGIS 10.1 (ESRI, Inc.).

The transmitted dive data consisted of abstracted time/ depth profiles for each dive for which information was successfully transmitted. In order to obtain reasonable estimates of time spent within the bottom phases of dives from the relatively low-resolution dive profiles, we calculated a series of interpolated time-depth points for each dive profile, assuming a constant swim speed and direction between transmitted points, thereby increasing the number of time-depth points to 21 for each profile following McIntyre et al. (2010). After calculating the estimated time spent within the bottom $20 \%$ of each dive (bottom time), we used linear regressions to quantify the relationship between maximum dive depth, dive duration and bottom time for each seal (Bailleul et al. 2008). Residuals from the regressions were then used to identify dives of increased 'forage effort', based on above-average amounts of time spent at the bottoms of dives and accounting for differences in dive depth and duration.

\section{Environmental variables}

Seafloor depth estimates were extracted from the GEBCO Digital Atlas (IOC et al. 2003) for each dive location estimate as provided by the tag manufacturer (Sea Mammal Research Institute, University of St. Andrews). In situ temperature measurements were recorded and transmitted from the CTD-SRDLs. Temperature profiles were inspected visually using Ocean Data View (Schlitzer 2002) and unrealistic or incomplete profiles removed. Temperature profiles were considered unrealistic when they contained extreme outlying values $\left(<-3{ }^{\circ} \mathrm{C}\right.$ or $\left.>5{ }^{\circ} \mathrm{C}\right)$ and/or values within the same profile that differed by more than $40 \%$ from preceding or subsequent values. For each of the filtered profiles, we calculated the maximum temperature value within the profile $\left(T_{\max }\right)$, the depth of $T_{\max }$ ( $\left.T_{\text {max depth }}\right)$ and the difference between the maximum and minimum temperatures recorded $\left(T_{\text {diff }}\right)$.

\section{Environmental influences on dive behaviour}

We used a series of linear mixed effects models to identify the relative influences of a number of environmental variables on dive behaviour parameters. Since all seals displayed a bimodal pattern of depth use (see Results and Discussion), we considered dive parameters for shallow dives $(<75 \mathrm{~m})$ and deep dives $(\geq 75 \mathrm{~m})$ separately. Foraging activity was detected during both shallow and deep dives performed by adult female Weddell seals equipped with mandible accelerometers at the same time of this study and at the same location (not included in this study) (Naito et al. 2010). We therefore investigated the influences of environmental parameters on dive behaviours associated with both shallow and deep dives. Dive parameters included in the analyses were dive duration $(D D U R)$ and relative amount of time spent at the bottom of dives (BT.RESID), as well as the daily ratio between the number of transmitted shallow and deep dives (SHAL$\left.L O W . D E E P_{\text {ratio }}\right)$. Plots of the dive data showed no evidence of substantial diel vertical migration in dive behaviour by the seals in our study (most likely due to limited variability in diel light intensity during mid-summer-see Watanabe et al. (2003) for similar findings during mid-summer). We therefore excluded the potential influence of differences in light intensity associated with time of day on the dive behaviour of tracked seals. The CTD sampling protocol of the instruments (see Boehme et al. 2009 for details) resulted in a maximum of only 4 CTD profiles transmitted per seal per day (mean number of profiles in our study: $2.1 \pm 1)$. These profiles furthermore do not necessarily correspond to individual dive profiles in space or time due to temporary storage of profiles onboard the tags prior to transmission. Behavioural and environmental variables were therefore averaged to daily values. Our starting full models were:

$$
\begin{aligned}
& \mathrm{Par} \sim \mathrm{SF}_{\text {depth }}+T_{\max }+T_{\text {max } \cdot \text { dep }}+T_{\text {diff }}+\mathrm{SEX} \\
& \quad+\text { AGE.CLASS }+i_{\text {seal }}
\end{aligned}
$$

where Par either DDUR, BT.RESID or SHAL$L O W . D E E P_{\text {ratio }}, S F_{\text {depth }}$ seafloor depth $(\mathrm{m}), T_{\max }$ maximum temperature $\left({ }^{\circ} \mathrm{C}\right), T_{\text {max.dep }}$ depth of $T_{\max }(\mathrm{m}), T_{\text {diff }}$ temperature difference between maximum and minimum temperature $\left({ }^{\circ} \mathrm{C}\right)$ and $i_{\text {seal }}$ individual seal (random term).

Initial models consisted of all fixed effects. Model selection was based on maximum likelihood and using second-order AIC (AICc) and corresponding AIC weights to select the most parsimonious models (Burnham and Anderson 2002). We used a number of different plot types to assess model fits, as well as temporal autocorrelation in model residuals (Pinheiro and Bates 2004). Variance component analyses were carried out on all final models to estimate variation explained by the random term (RE). We further calculated a marginal $R^{2}$ value for all models, providing an estimate of the variance explained by the fixed effects (Nakagawa and Schielzeth 2013). All analyses were undertaken in the $R$ statistical environment (R Core Team 2012). We used the package nlme (Pinheiro et al. 2008) for mixed effect model analyses. Unless otherwise stated, mean values \pm SD are reported. Statistical significance was set at $p \leq 0.05$. 


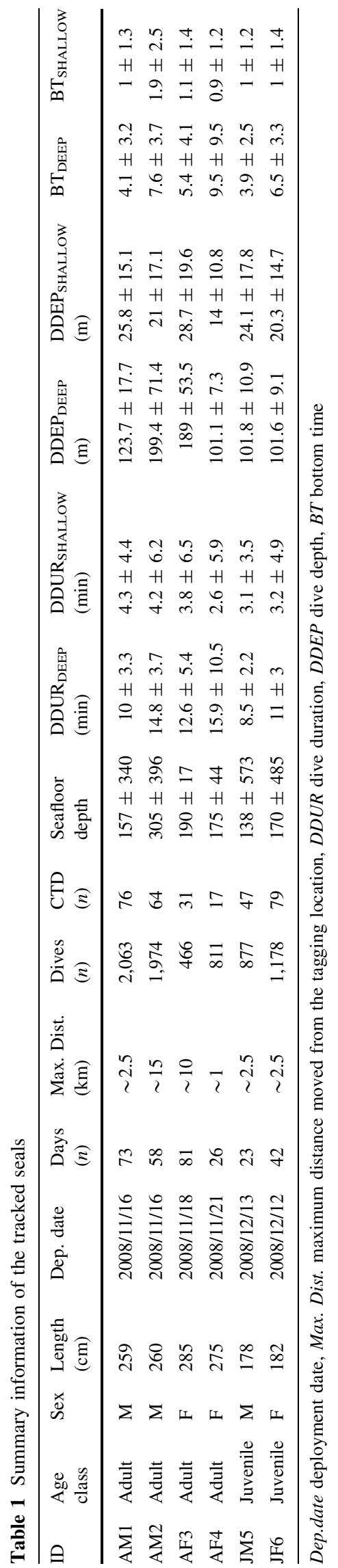

\section{Results and discussion}

Data transmissions continued for a mean period of 50.5 days (min: 23; max: 81) and a total of 7,369 dive profiles, and 314 CTD profiles were successfully transmitted (Table 1). A total of 2,942 location estimates were obtained, of which 1,357 were retained after filtering. All tracked seals remained in the vicinity of Atka Bay for the duration of the tracking period (Fig. 1), and none moved further than approximately $15 \mathrm{~km}$ away from their individual tagging locations.

Dives

Dive depths recorded for all seals showed a bimodal pattern (Fig. 2), with high frequencies of shallow dives to depths less than $50 \mathrm{~m}$. Deep dives were concentrated around $100 \mathrm{~m}$ for seals AF4, JM5 and JF6. One adult male (AM2) and one adult female (AF3) displayed high numbers of deep dives to depths $>200 \mathrm{~m}$, while the remaining seal (AM1) concentrated its dives at depths between 100 and $150 \mathrm{~m}$. The bimodal patterns of dive depths are similar to that reported for seals tagged at the Drescher Inlet (Plötz et al. 2001), although seals there targeted deeper water layers close to the seafloor in the region of $400 \mathrm{~m}$, where evidence for foraging (based on jaw movement data) was also reported by Liebsch et al. (2007).

Seals AM1, AF4, JM5 and JF6 displayed increased bottom times when diving to similar depths, compared to the depths they most often dived to (Fig. 2). Interestingly, seals AM2 and AF3 showed increased bottom times also at dive depths that were not frequently targeted as compared to other dive depths. For example, seal AM2 displayed increased bottom times when diving to depths in the region of $75 \mathrm{~m}$ (Fig. 2), although this depth was not frequently targeted (Fig. 2). Similarly, seal AF3 displayed long bottom times when diving to depths between approximately 100 and $175 \mathrm{~m}$, yet this dive depth was not frequented very often. The same two seals displayed the greatest spatial movements of all seals in our sample. We therefore consider the dives with increased bottom times, but to dive depths not often utilised, a likely artefact of dives performed in areas where the seals did not spend substantial amounts of time. That is, seals also performed some dives with above-average bottom times in areas where they were passing through and not concentrating their dive activity. Such increased bottom times in this depth range could also result from ice-associated foraging. In a parallel study at Atka Bay, an adult Weddell seal carrying a short-term deployment of a mandible accelerometer and camera logger (no CTD-SRDL and not included in this study) often concentrated its foraging at depths of around $75 \mathrm{~m}$, where it apparently fed on smaller prey items as inferred from jaw 

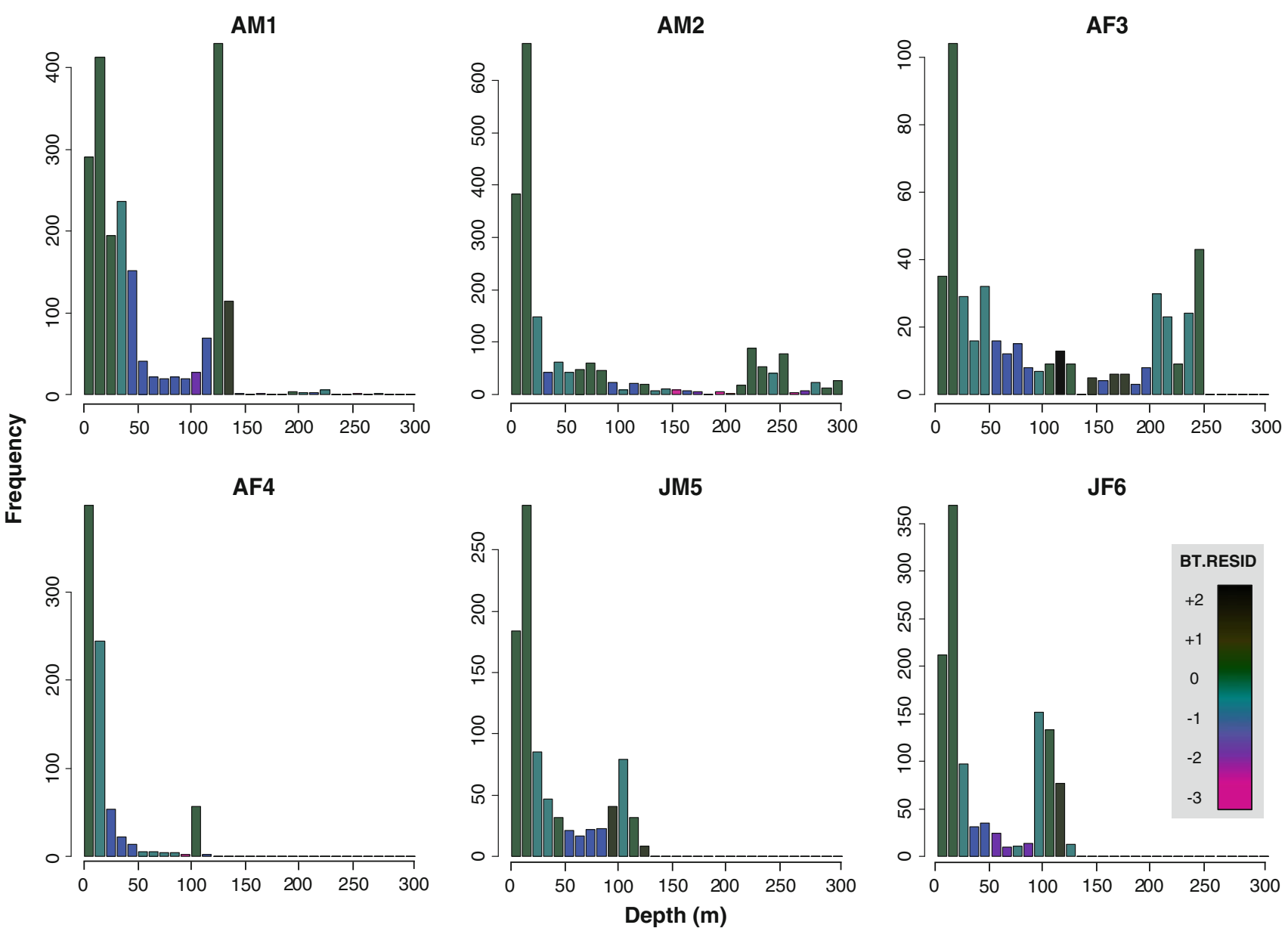

Fig. 2 Colour-coded histograms showing the averaged bottom time residuals per dive depth category, as well as the bimodal dive depth distributions of tracked Weddell seals. BT.RESID averaged bottom time residuals

movement amplitudes (Naito et al. 2010). Based on the photographic images obtained from these foraging dives, they were further interpreted to be associated with the underside of an iceberg which was hypothesised to potentially host a similar cryo-benthic community of marine invertebrates as described by Watanabe et al. (2006). Such a community of invertebrates would likely attract potential prey species for Weddell seals and may therefore help explain the pelagic mode depths reported here.

\section{Environmental influences}

Predicted seafloor depths (GEBCO) for dive locations varied substantially throughout the tracking periods for most seals (Table 1, e.g. Fig. S1, Online Resource 1). The comparative consistency of maximum dive depths within areas (e.g. Fig. S1) suggested that such dives were likely to the seafloor and that the true seafloor depth could therefore possibly be indicated by the maximum dive depths obtained by tracked seals within specific areas (as illustrated by Padman et al. 2010 for elephant seal dives). Temperature profiles of seals that utilised similar areas during the same time period showed good agreement (Fig. S2, Online Resource 1). Water temperatures remained relatively constant $\left(\sim-1.9^{\circ} \mathrm{C}\right)$ throughout the time period that seals were tracked (Figs. S2 and S3), with a slight increase in shallow water temperatures detected during January 2009. Some warming (up to $\sim-1.5^{\circ} \mathrm{C}$ ) was evident in the upper $100 \mathrm{~m}$ of the water column used by Seal AM2 from mid-December 2008 (Fig. S3), corresponding to the time that the seal moved north and westwards away from its tagging location (Fig. 1).

The most parsimonious models excluded sex and age class for all dive parameters (Table 2). The lack of an age or sex class effect may be an artefact of the limited sample size of our study, since such effects on dive behaviour are known for other populations (e.g. Burns 1999). Final models explained differing amounts of the variance, ranging from $\sim 2$ to $40 \%$ ( $\mathrm{RE}+R_{\text {marginal }}^{2}$, Table 2$)$. The smaller amounts of variance explained were evidently related to some of the final models only retaining one fixed 


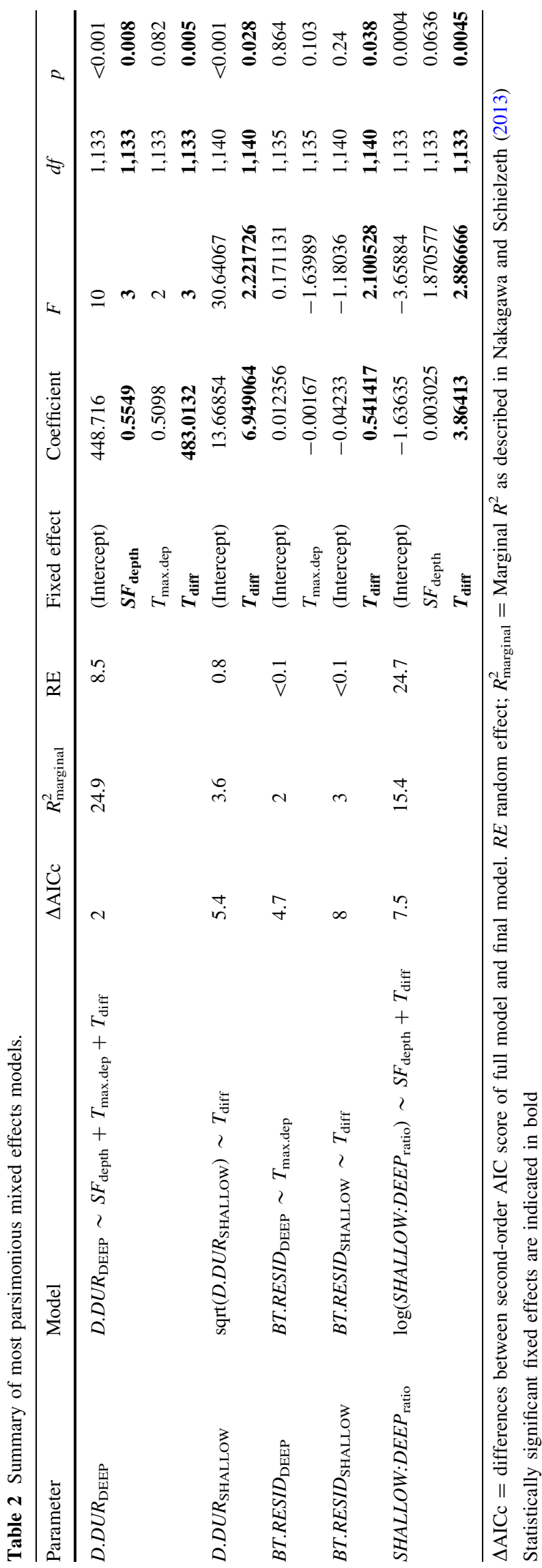

effect. Seafloor depth $\left(\mathrm{SF}_{\text {depth }}\right)$ displayed a significant positive relationship with deep dive durations (Table 2). This was not surprising, because many of the deep dives performed by seals in our study were evidently to the seafloor (or at least in very close proximity to the seafloor). A weak but significant linear relationship existed between dive depths and dive durations for seals in our study $\left(y=0.03 x+7.02 ; F_{1,2032}=443.9 ; p<0.001\right)$. It therefore follows that when seals were performing dives to the seafloor in deeper areas, the dive durations increased correspondingly.

Model outputs indicated significant positive relationships between $T_{\text {diff }}$ and a number of dive parameters (Table 2). Dive durations (both deep and shallow) increased with increases in $T_{\text {diff, }}$, while a significant positive relationship existed for the ratio of shallow:deep dives with $T_{\text {diff }}$ (Table 2). Furthermore, shallow dives were characterised by increased bottom times when performed in water masses with higher $T_{\text {diff }}$ (Table 2). These results indicate that seals tended to perform more deep dives, which were comparatively longer, when the water column was more stratified, compared to dives performed when the water temperatures were more homogenous and mixed. While we have no diet information for the seals studied, dives to the seafloor are possibly associated with foraging on benthic prey such as Trematomus spp. (Burns et al. 1998).

At the same time, shallow dives were characterised by increased durations and increased bottom times when seals were diving in more stratified water. We interpret this as indicating that seals increased their foraging effort within specific depth layers (both shallow and deep in close proximity to the seafloor), when the water column showed greater stratification. This can likely be explained by potential prey species occurring in more concentrated numbers within preferred temperature layers when there is more stratification in temperature through the water column, whereas prey species are more likely to be scattered in the water column when the temperature structure is relatively well mixed (Takahashi et al. 2008). Indeed, the vertical distribution of Pleuragramma antarcticum, a known prey species of Weddell seals, was associated closely with the vertical structure of the water column when a clear pycnocline was present (Plötz et al. 2001). Seals may therefore take advantage of increased concentrations of prey by maximising their forage effort in appropriate depth layers.

Our results agree well with previous studies suggesting that prey distribution of Weddell seals (and therefore their foraging behaviour) is influenced by water characteristics (e.g. Heerah et al. 2013). However, due to the relatively short-term nature of our dataset, our study did not take into account the potential influences on dive behaviour of 
factors such as localised prey depletion (e.g. Thums et al. 2013), development of foraging skills in young seals (e.g. Burns 1999) and differences in foraging behaviour associated with seasonal influences (Lake et al. 1997). Future longer-term studies should aim to also include such variables in assessments of environmental influences on dive behaviour.

\section{Conclusion}

Weddell seals from Atka Bay displayed typical bimodal distributions in dive depths and evidently concentrated their foraging efforts in shallow water depths of $<50 \mathrm{~m}$, as well as deeper depths in close proximity to the seafloor. Changes in the vertical temperature stratification of the water column influenced the dive behaviour of tracked seals, which tended to increase their foraging effort when performing both shallow and deep dives. We hypothesise that this is likely the result of increased water temperature stratification concentrating prey species within specific water depth layers.

Acknowledgments The Alfred-Wegener-Insitut, Helmholtz-Zentrum für Polar-und Meeresforschung (AWI) provided financial and logistical support for the fieldwork undertaken from Neumayer Station, Antarctica. Permits to conduct this research were issued according to the 'Gesetz zur Ausführung des Umweltschutzprotokolls vom 4. Okt 1991 zum Antarktis-Vertrag' by the German Federal Envionmental Agency (I 3.5-94003-3/219) and the Gesetz zum Übereinkommen vom 1. Jun 1972 zur Erhaltung der antarktischen Robben (CCAS) by the German Federal Agency for Nature Conservation (Z.3-27 UIG). Dr. Christine Wesche (AWI, Section Polar Meteorology, EOS Group) processed the Envisat ASAR images (provided by ESA: CAT-1, 5024). TM was supported by an International Climate Protection Fellowship from the Alexander von Humboldt Stiftung during part of the data analyses and writing of this paper. We thank two anonymous reviewers for their constructive comments that improved this manuscript.

Open Access This article is distributed under the terms of the Creative Commons Attribution License which permits any use, distribution, and reproduction in any medium, provided the original author(s) and the source are credited.

\section{References}

Bailleul F, Pinaud D, Hindell M, Charrassin J-B, Guinet C (2008) Assessment of scale-dependent foraging behaviour in southern elephant seals incorporating the vertical dimension: a development of the first passage time method. J Anim Ecol 77:948-957

Bestley S, Jonsen ID, Hindell MA, Guinet C, Charrassin J-B (2013) Integrative modelling of animal movement: incorporating in situ habitat and behavioural information for a migratory marine predator. Proc Royal Soc B 280:20122262
Boehme L, Lovell P, Biuw M, Roquet F, Nicholson J, Thorpe SE, Meredith MP, Fedak M (2009) Technical note: animal-borne CTD-satellite relay data loggers for real-time oceanographic data collection. Ocean Sci 5:685-695

Bornemann H, Mohr E, Plötz J, Krause G (1998) The tide as zeitgeber for Weddell seals. Polar Biol 20:396-403

Burnham KP, Anderson DR (2002) Model selection and multimodel inference: a practical information-theoretic approach, 2nd edn. Springer Science+Business Media, New York

Burns JM (1999) The development of diving behavior in juvenile Weddell seals: pushing physiological limits in order to survive. Can J Zool 77:734-747

Burns JM, Trumble SJ, Castellini MA, Testa JW (1998) The diet of Weddell seals in McMurdo Sound, Antarctica as determined by scat collections and stable isotope analysis. Polar Biol 19:272-282

Burns JM, Castellini MA, Testa JW (1999) Movements and diving behavior of weaned Weddell seal (Leptonychotes weddellii) pups. Polar Biol 21:23-36

Davis RW, Fuiman LA, Williams TM, Horning M, Hagey W (2003) Classification of Weddell seal dives based on 3-dimensional movements and video-recorded observations. Mar Ecol Prog Ser 264:109-122

Fossette S, Hobson VJ, Girard C, Calmettes B, Gaspar P, Georges J-Y, Hays GC (2010) Spatio-temporal foraging patterns of a giant zooplanktivore, the leatherback turtle. J Marine Syst $81: 225-234$

Freitas C, Lydersen C, Fedak M, Kovacs KM (2008) A simple new algorithm to filter marine mammal Argos locations. Mar Mamm Sci 24:315-325

Harcourt RG, Hindell MA, Bell DG, Waas JR (2000) Threedimensional dive profiles of free-ranging Weddell seals. Polar Biol 23:479-487

Heerah K, Andrews-Goff V, Williams G, Sultan E, Hindell M, Patterson T, Charrassin J-B (2013) Ecology of Weddell seals during winter: influence of environmental parameters on their foraging behaviour. Deep Sea Res Part II 88-89:23-33

Holdo RM, Roach RR (2013) Inferring animal population distributions from individual tracking data: theoretical insights and potential pitfalls. J Anim Ecol 82:175-181

IOC, IHO, BODC (2003) "Centenary edition of the GEBCO digital atlas", published on CD-ROM on behalf of the intergovernmental oceanographic commission and the international hydrographic organization as part of the general bathymetric chart of the oceans. British Oceanographic D, Liverpool

James BS, McIntyre T, Tosh CA, Bornemann H, Plötz J, Bester MN (2012) Inter-population differences in diving behaviour of adult male southern elephant seals (Mirounga leonina). Polar Biol 35:1759-1766

Lake SE, Burton HR, Hindell MA (1997) Influence of time of day and month on Weddell seal haul-out patterns at the Vestfold Hills, Antarctica. Polar Biol 18:319-324

Liebsch N, Wilson RP, Bornemann H, Adelung D, Plötz J (2007) Mouthing off about fish capture: jaw movement in pinnipeds reveals the real secrets of ingestion. Deep-Sea Res Part II $54: 256-269$

McIntyre T, de Bruyn PJN, Ansorge IJ, Bester MN, Bornemann H, Plötz J, Tosh CA (2010) A lifetime at depth: vertical distribution of southern elephant seals in the water column. Polar Biol 33:1037-1048

McIntyre T, Ansorge IJ, Bornemann H, Plötz J, Tosh CA, Bester MN (2011) Elephant seal dive behaviour is influenced by ocean temperature: implications for climate change impacts on an ocean predator. Mar Ecol Prog Ser 441:257-272

Naito Y, Bornemann H, Takahashi A, McIntyre T, Plötz J (2010) Fine-scale feeding behavior of Weddell seals revealed by a mandible accelerometer. Polar Sci 4:309-316 
Nakagawa S, Schielzeth H (2013) A general and simple method for obtaining $R^{2}$ from generalized linear mixed-effects models. Method Ecol Evol 4:133-142

Padman L, Costa DP, Bolmer T, Goebel ME, Huckstadt LA, Jenkins A, McDonald BI, Shoosmith DR (2010) Seals map bathymetry of the Antarctic continental shelf. Geophys Res Lett 37:L21601

Pinheiro JC, Bates DM (2004) Mixed-effects models. In: Chambers J, Eddy W, Härdle W, Sheather S, Tierney L (eds) S and S-Plus. Springer, New York, NY

Pinheiro J, Bates D, DebRoy S, Sarkar D (2008) nlme: linear and nonlinear mixed effects models. $\mathrm{R}$ package version 3.1-105

Plötz J, Bornemann H, Knust R, Schröder A, Bester M (2001) Foraging behaviour of Weddell seals, and its ecological implications. Polar Biol 24:901-909

R Core Team (2012) R: a language and environment for statistical computing. R Foundation for Statistical Computing, Vienna, Austria

Roquet F, Charrassin J-B, Marchand S, Boehme L, Fedak M, Reverdin G, Guinet C (2011) Delayed-mode calibration of hydrographic data obtained from animal-borne satellite-relay data loggers. J Atmos Ocean Tech 28:787-801

Sato K, Mitani Y, Cameron MF, Siniff DB, Watanabe Y, Naito Y (2002) Deep foraging dives in relation to the energy depletion of Weddell seal (Leptonychotes weddellii) mothers during lactation. Polar Biol 25:696-702

Sato K, Mitani Y, Cameron MF, Siniff DB, Naito Y (2003) Factors affecting stroking patterns and body angle in diving Weddell seals under natural conditions. J Exp Biol 206:1461-1470
Schlitzer R (2002) Interactive analysis and visualization of geoscience data with Ocean Data View. Comput Geosci 28:1211-1218

Southwell C, Bengtson JL, Bester M, Blix AS, Bornemann H, Boveng P, Cameron MF, Forcada J, Laake J, Nordøy ES, Plötz J, Rogers T, Southwell D, Steinhage D, Stewart BS, Trathan P (2012) A review of data on abundance, trends in abundance, habitat use and diet of ice-breeding seals in the Southern Ocean. CCAMLR Sci 19:49-74

Takahashi A, Matsumoto K, Hunt GL, Shultz MT, Kitaysky AS, Sato K, Iida K, Watanuki Y (2008) Thick-billed murres use different diving behaviors in mixed and stratified waters. Deep Sea Res Part II 55:1837-1845

Thums M, Bradshaw CJ, Sumner MD, Horsburgh JM, Hindell MA (2013) Depletion of deep marine food patches forces divers to give up early. J Anim Ecol 82:72-83

Van Opzeeland I, Parijs S, Frickenhaus S, Kreiss CM, Boebel O (2012) Individual variation in pup vocalizations and absence of behavioral signs of maternal vocal recognition in Weddell seals (Leptonychotes weddellii). Mar Mamm Sci 28:E158-E172

Watanabe Y, Mitani Y, Sato K, Cameron M, Naito Y (2003) Dive depths of Weddell seals in relation to vertical prey distribution as estimated by image data. Mar Ecol Prog Ser 252:283-288

Watanabe Y, Bornemann H, Liebsch N, Plötz J, Sato K, Naito Y, Miyazaki N (2006) Seal-mounted cameras detect invertebrate fauna on the underside of an Antarctic ice shelf. Mar Ecol Prog Ser 309:297-300

Williams TM, Fuiman LA, Horning M, Davis RW (2004) The cost of foraging by a marine predator, the Weddell seal Leptonychotes weddellii: pricing by the stroke. J Exp Biol 207:973-982 